\title{
Effect of Plyometric Training for Development of Speed among High Jumpers of India
}

\author{
Hiremath Rajashekhar Mallikarjunayya \\ Physical Education and Welfare office \\ University of Horticultural Sciences \\ Bagalkot, India \\ pressports9@gmail.com
}

\begin{abstract}
-plyometric, also known as "jump training" or "plyos", are exercises based around having muscles exert maximum force in as short a time as possible, with the goal of increasing both speed and power. The objective of the study is to determine the effect of plyometric exercises for development of speed among High Jumpers of Karnataka. It is hypothesized there will be effect of Plyometric training for development of Speed among High Jumpers. The purpose of the present study to find out the effect of plyometric training for the development of Speed in High Jump. The sample for the present study consists of 40 Male High Jumpers of Karnataka out of which 20 are experimental group and 20 are controlled group. Plyometric exercises such as hopping, bounding, depth jumps, tuck jumps, box jumps etc. were given to experimental group on alternate days i.e. three sessions per week and controlled group were given the general training in High Jump for eight weeks. To assess the Speed Pre Test and Post Test were conducted in 50 Meters Run by the qualified technical officials of athletics to the experimental group and controlled group .This study shows that due to the plyometric exercises there is a improvement of High Jump experimental group in speed and High Jump controlled group is decreased in performance ability and speed due to the general training. High Jumping is all about explosive power. Explosive power is a combination of speed, muscular endurance and muscular strength, all of which can be developed through plyometric exercises. It is concluded that due to plyometric training there will be improvement in speed among High Jumpers.
\end{abstract}

Keywords-plyometric exercise, speed, explosive power

\section{INTRODUCTION}

Plyometrics, also known as "jump training" or "plyos", are exercises in which muscles exert maximum force in short intervals of time, with the goal of increasing power (speedstrength). This training focuses on learning to move from a muscle extension to a contraction in a rapid or "explosive" manner, such as in specialized repeated jumping. Plyometrics are primarily used by athletes, especially martial artists, sprinters and high jumpers, to improve performance, and are used in the fitness field to a much lesser degree. Plyometrics is a suitable form of power training for many team and individual sports. High Jumpers today are bigger, faster and more explosive than ever before. Explosive Strength defined as the rate of force development at the onset of the contraction. The goal of training Plyometric training is to improve the rate of force development to create more force in less time for the optimum results

The high jump is a track and field event in which competitors must jump unaided over a horizontal bar placed at measured heights without dislodging it. In its modern most practised format, a bar is placed between two standards with a crash mat for landing. At the elite level, athletes run towards the bar and use the Fosbury Flop method of jumping, leaping head first with their back to the bar. Performed since ancient times, competitors have introduced increasingly more effective techniques to arrive at the current form.The discipline is, alongside the pole vault, one of two vertical clearance events to feature on the Olympic athletics programme. It is contested at the World Championships in Athletics and IAAF World Indoor Championships, and is a common occurrence at track and field meetings. The high jump was among the first events deemed acceptable for women, having been held at the 1928 Olympic Games. Javier Sotomayor (Cuba) is the current men's record holder with a jump of $2.45 \mathrm{~m}$ ( $8 \mathrm{ft} 01 / 4 \mathrm{in}$ ) set. In 1993 - the longest standing record in the history of the men's high jump. Stefka Kostadinova (Bulgaria) has held the women's world record at $2.09 \mathrm{~m} \mathrm{(6} \mathrm{ft} \mathrm{101/4} \mathrm{in)} \mathrm{since} \mathrm{1987,} \mathrm{also} \mathrm{the} \mathrm{longest-held} \mathrm{record}$ in the event.

A. Joe Vimal Raj Studied the effect of plyometric training on selected physical fitness components among college men long jumpers [1]. To achieve the purpose of the study twenty male long jumpers have been randomly selected from various colleges in the state of Tamil Nadu, India. The age of subjects were ranged from 18 to 25 years. The subjects had past experience of at least three years in long jump and only who those represented their respective college teams were taken as subjects. A series of physical tests was carried out on each participant. These included Speed assessed by 30 meters dash, vertical explosive strength assessed by vertical jump and horizontal explosive strength assessed by standing broad jump. The subjects were randomly assigned into two groups of ten each, such as experimental and control groups. The experimental group participated in the plyometric training for 3 days a week, one session per day and for 8 weeks each session lasted 90 minutes. The control group maintained their daily routine activities and no special training was given. The subjects of the two groups were tested on selected variables prior and immediately after the training period. The collected data were analyzed statistically through analysis of covariance (ANCOVA) to find out the significance difference. The 0.05 level of confidence was fixed to test the level of significance difference in any between groups. The results of the study showed that there was significant level differences exist between plyometric training group and control group. And also plyometric training group showed significant improvement on speed, vertical explosive strength and horizontal explosive strength compared to control group. 


\section{Techniques in high jump}

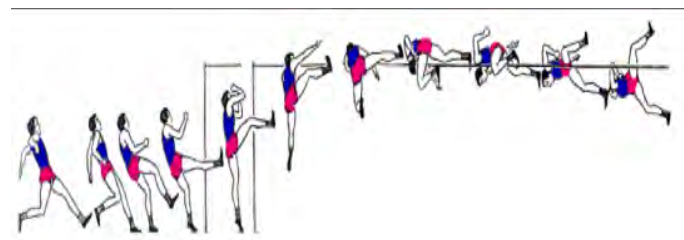

Fig. 1. Straddle Technique

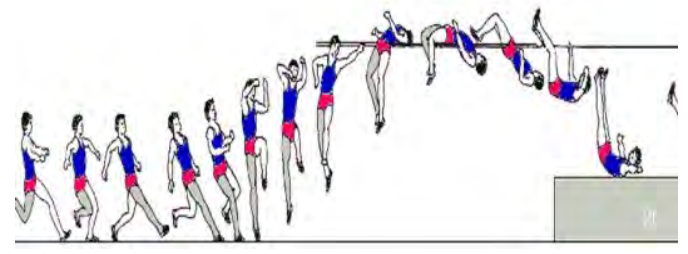

Fig. 2. Fosbury Flop

\section{METHOD}

The purpose of the present study to find out the effect of plyometric exercises for the development of speed among High Jumpers of Karnataka state. The sample for the present study consists of 40 Male High Jumpers of Karnataka out of which 20 are experimental group and 20 are controlled group. Plyometric exercises such as hopping, bounding, depth jumps, tuck jumps, hurdle jumps etc were given to experimental group on alternate days i.e. three sessions per week for eight weeks along with the High Jump training and controlled group were given the general training of High jump Pre Test and Post Test were the $50 \mathrm{M}$ Run to measure the speed among experimental group and controlled group.

\section{RESULT}

TABLE I. MeAn VALues Of 50 M Run Test BetweEn EXPERIMENTAL AND CONTROL GROUP OF HIGH JUMPERS

\begin{tabular}{|c|c|c|c|c|c|}
\hline Variables & Group & $\begin{array}{c}\text { Pre } \\
\text { Test } \\
\text { Mean } \\
\pm \text { SD }\end{array}$ & $\begin{array}{c}\text { Post } \\
\text { Test } \\
\text { Mean } \\
\pm \text { SD }\end{array}$ & $\mathbf{t}$ & P - Value \\
\hline \multirow{2}{*}{$\begin{array}{l}50 \mathrm{M} \\
\text { Run Test }\end{array}$} & Experimental & $\begin{array}{l}7.51 \\
\pm 0.294\end{array}$ & $\begin{array}{l}7.23 \\
\pm 0.262\end{array}$ & \multirow{2}{*}{4.58} & \multirow{2}{*}{0.000} \\
\hline & Control & $\begin{array}{l}7.64 \\
\pm 0.376\end{array}$ & $\begin{array}{l}7.73 \\
\pm 0.408\end{array}$ & & \\
\hline
\end{tabular}

*Significant at 0.05 level

This results of the study shows that due to the plyometric training there is a improvement of experimental group in the Speed and controlled group is decreased in performance due to the general training. The Experimental Group of $50 \mathrm{M}$ Run Men is 7.51 in Pre Test and Controlled Group mean is 7.64 in Pre Test there is a difference of 0.13 in Pre Test. The Experimental Group Mean is 7.23 in Post Test an Controlled Group mean is 7.73, the Experimental Group mean in Post Test in $50 \mathrm{M}$ Run is decreased from 7.51 to 7.23 the control Group mean in Post Test in 50 M Run is increased from 7.64 to 7.73. Due to the Plyometric Training, the Experimental group has improved a lot.

\section{DISCUSSION}

The Strength, Speed and Endurance are the important abilities for successful performance. The dominant ability is the one from which the sport requires higher contribution to achieve the high success in the sports and games. Most sports require peak performance in at least two abilities. The Relationships among strength, Speed, and endurance create crucial physical athletic qualities. Specific development of a bio motor ability must be methodical. A developed dominant ability directly or indirectly effects the other motor abilities. When an athlete develops strength, he may experience a positive transfer to speed and endurance. On the other hand, a strength-training program designed only to develop maximum strength may negatively affect the development of aerobic endurance. A high jumper propelling himself off the ground requires explosive strength and speed for better performance. A High Jumper ability to display a high level of explosive power is believed to be one of the most important factors in determining athletic success.

\section{CONCLUSIONS}

It is concluded that the due to the Plyometric training develops the strength and power in the legs. It also improve the co-ordination in the arms and legs and promotes in developing the Speed. In this Study it is concluded that due to the Plyometric Training there is a development of Speed among High jumpers.

\section{RECOMMENDATIONS}

Similar Studies can be conducted among females and in other Sports and games. This study is useful to the Coaches to prepare the conditioning program to improve the motor abilities of the Jumpers.

\section{ACKNOWLEDGMENTS}

I am very thankful to Athletics Coach for giving the Training to the High Jumpers and also to the Technical official for conducting the $50 \mathrm{M}$ Run and there help for the Study.

\section{REFERENCES}

[1] A. J. V. Raj, "Effect of plyometric exercise training on selected physical fitness components among long jumper". Journal of International Academic Research for Multidisciplinary, 2013. 